Int. J. Dev. Biol. 55: 59-64 (2011)

doi: $10.1387 / \mathrm{ijdb} .103083 \mathrm{mr}$

\title{
Contribution of mesoderm to the developing dental papilla
}

\author{
MICHAELA ROTHOVÁ ${ }^{1,2,3}$, JIFAN FENG ${ }^{1}$, PAUL T. SHARPE1, RENATA PETERKOVÁ \\ and ABIGAIL S. TUCKER*,1
}

\begin{abstract}
${ }^{1}$ Department of Craniofacial Development and Orthodontics, King's College London, London, UK, ${ }^{2}$ Institute of Experimental Medicine, Academy of Sciences of the Czech Republic, v.v.i., Prague and ${ }^{3}$ Department of Cell Biology, Faculty of Science, Charles University, Prague, Czech Republic
\end{abstract}

\begin{abstract}
Teeth develop from epithelium and neural crest-derived mesenchyme via a series of reciprocal epithelial-mesenchymal interactions. The majority of the dental papilla of the tooth has been demonstrated to be of neural crest origin. However, non-neural crest cells have also been observed in this region from the bud stage of tooth development onwards. The number of these non-neural crest-derived cells rises as the dental papilla develops. However, their origin is unknown. We have followed migration of cells into the tooth in vitro using Dil to fate map regions surrounding the developing tooth. To identify the contribution of mesodermally-derived cells, we have utilised Mesp1cre/R26R transgenic reporter mice. We document that cells outside the early tooth primordium migrate into the developing dental papilla from the late cap stage of development. Here, we show that migrating cells are mesodermally-derived and create a network of endothelial cells, forming the blood vessels of the tooth. No cells of mesodermal origin were present in the condensed mesenchyme surrounding the dental epithelium until the cap stage of tooth development. Mesodermally-derived cells start invading the dental papilla at the late cap stage, providing the blood supply to the dental pulp. Endothelial cells are able to invade the developing dental papilla in vitro using the slice culture method. Understanding the origin and timing of migration of the mesodermally-derived cells is an important advance in our understanding of how a tooth develops and is particularly relevant to studies which aim to create bioengineered teeth.
\end{abstract}

KEY WORDS: tooth, dental papilla, Mesp1cre, mesoderm, endothelial cells

\section{Introduction}

Teeth develop from dental epithelium and neural crest-derived mesenchyme driven by reciprocal interactions. The dental epithelium invaginates into the surrounding dental mesenchyme to form a tooth bud. The dental epithelium starts to fold to produce a cap shape, with the mesenchymal dental papilla forming between the extending epithelial cervical loops. The dental papilla goes on to form the dental pulp at the centre of the tooth. The dental mesenchyme has been shown to be of neural crest cell origin, by using a Wnt1cre/R26R reporter mouse (Chai et al. 2000). However, these authors also reported the presence of some nonneural crest cells from the bud stage of tooth development onwards. As the tooth develops to the cap and bell stages, an increasing number of non-neural crest cells were observed in the dental papilla. This dynamic distribution of neural crest cellderived tissue was attributed to differential proliferation of nonneural crest derived cells and/or possible apoptosis of neural crest cells (Chai et al. 2000). The number of non-neural crest cells

\footnotetext{
Abbreviations used in this paper: $\mathrm{E}$, embryonic day; IDE, inner dental epithelium; M1, first lower molar; Mesp1cre/R26R, Cre-recombinase expressed under the control of the Mesp1 promoter as a transgene crossed with the ROSA26 conditional reporter (R26R); ODE, outer dental epithelium; P, postnatal; VEGF, vascular endothelial growth factor; Wnt1cre/R26R, cre-recombinase expressed under the control of the Wntl promoter as a transgene crossed with the ROSA26 conditional reporter (R26R); X-Gal, $\beta$ substrate (bromochloro-indolyl-galactopyranoside)
}

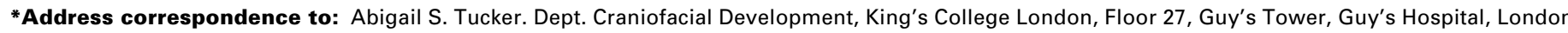

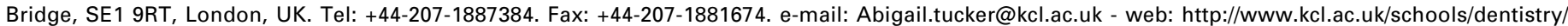
research/cell/tucker 
in the dental papilla can also increase as a result of immigration of cells. In support of this, when wild-type tooth germs were dissected at the cap stage and implanted into $L a c Z$ ( $\beta$-galactosidase) or GFP (Green Fluorescent Protein) reporter host mice, an influx of host derived cells into the dental papilla was observed after a week to two weeks of development (Cho et al. 2003; Nait Lechguer et al. 2008).

During tooth development blood vessels and nerves move into the developing dental papilla (the prospective tooth pulp) to provide nutrients, oxygen and innervation. The non-neural crest derived cells in the early bell stage papilla might therefore represent endothelial or neuronal cell types. Nerves are found within the branchial (pharyngeal) arches at the earliest stages of tooth development but remain far from the tooth region itself (Mohamed and Atkinson 1983). At the cap stage a network of nerves forms under the tooth with fibres moving into the dental follicle which surrounds the tooth. Nerve fibres do not enter the papilla however, until cytodifferentiation is well underway, which for the first molar occurs a few days after birth (Mohamed and Atkinson 1983). The non-neural crest cells in the papilla at the bell stage are therefore unlikely to be due to the influx of neuronal cell types. Blood vessels, in contrast, are present in the papilla at a much earlier stage. In mouse embryo the endothelial cell markers are expressed in the central part of the future pulp from the early bell stage (E16.0) of the first lower molar (M1) (Nait Lechguer et al. 2008). There is thus a correlation between the expression of endothelial cell markers and the increase in non-neural crest cells in the papilla (Chai et al. 2000). It therefore seems likely that at least some of the non-neural crest derived cells in the dental papilla can be accounted for by an influx of endothelial cells.

In summary these data suggest that non-neural crest cells are present in the mouse dental mesenchyme at the bud stage (E13.5) and blood vessels are present in the dental papilla at the early bell stage (E16.0). However, it has not been proven whether the first capillary network rises de novo (vasculogenesis) or by an invasion of pre-existing capillaries (angiogenesis). We have therefore focused on the development of blood vessels in the dental tissue to verify the hypothesis that the cells of non-neural crest origin in the dental papilla are endothelial cells of mesodermal origin, which have migrated into the tooth.

The migration of cells into the dental papilla during tooth development was investigated using Dil to label the cells adjacent to the dental papilla in vitro. Previous studies have shown that no blood vessel-like structures could be detected in the dental pulp in tooth germs cultured in vitro (Nait Lechguer et al. 2008). This represents a serious problem for studying long-term tooth development in vitro as the health of the tooth germ is compromised. We therefore took advantage of the slice culture technique, in order to include the tissue that normally surrounds the tooth germ, thereby providing a more natural environment (Matalova et al. 2005; Cho et al. 2007; Diep et al. 2009).

To determine the nature of the non-neural crest cells in the dental papilla, we investigated the contribution of mesodermallyderived cells to the tooth using the Mesp1cre/R26R reporter mouse. Mesp1 is an early marker of mesoderm expressed from the onset of gastrulation (Saga et al. 1996). The Mesp1cre/R26R mouse allows the contribution of cells of mesodermal origin to be followed at any stage of mouse development (Saga et al. 1999) and has previously been used to describe the contribution of mesoderm to craniofacial development (McBratney-Owen et al. 2008; Yoshida et al. 2008). However, the contribution of mesodermally-derived cells to tooth development has not yet been described. Finally we investigated the identity of the mesodermally-derived cells using immunohistochemistry.

\section{Results}

\section{Movement of cells into the dental papilla in vitro}

Tissue slices have been shown to provide a good method of visualising tooth germs as they develop in vitro (Matalova et al. 2005; Cho et al. 2007; Diep et al. 2009) (Fig. 1 A,B). Here we show that this culture method also allows vascularisation of the developing dental papilla. For this we used $250 \mu \mathrm{m}$ slices of E14.5 mouse embryonic mandibles comprising the M1 tooth germ at the cap stage and cultured them for 4 days in vitro. To follow the blood vessel development during culture we used CD31 (PECAM-1) antibody as a specific endothelial marker (Newman et al. 1990). At the cap stage, the CD31 positive cells were present in the dental follicle surrounding the forming dental papilla (Fig. 1C). After 4 days in culture, the CD31 positive cells had entered the dental papilla, mimicking the expression observed in vivo (Fig. 1D) (Nait Lechguer et al. 2008).

To follow the fate of cells we labelled small groups of cells at the periphery of the condensed mesenchyme with a lipophilic dye Dil (Diekwisch 2002; Diep et al. 2009) on the tissue slices as described above (Fig. 2A). No movement of the labelled cells into the dental papilla was observed over the first 24 hours in culture but after 2 to 3 days, as the tooth germ reached the late cap/early bell stage, Dil labelled cells were observed delaminating from the
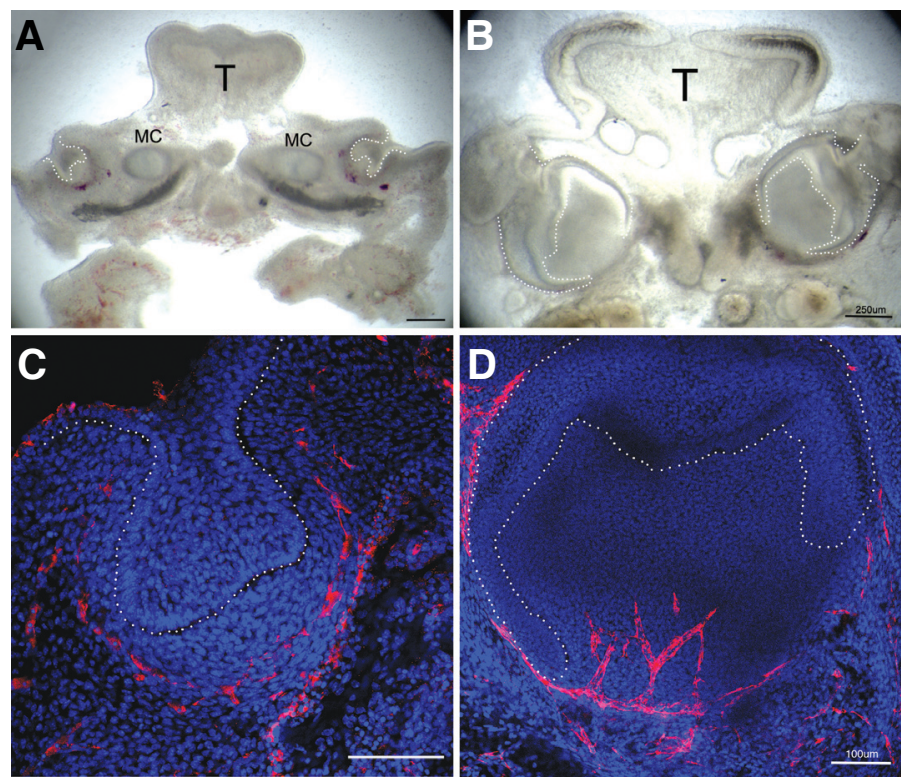

Fig. 1. Slice culture in vitro technique and the blood vessel invasion in vitro. (A) Slice of the E14.5 mouse mandible. (B) The same slice after 4 days in vitro culture. MC, Meckel cartilage; T, Tongue. (C,D) Sliced molar tooth germs. Nuclei stained in blue with Hoechst, CD31 positive cells in red. (C) E14.5. At this stage there are no CD31 positive endothelial cells in the forming dental papilla. (D) Molar tooth germ after 4 days in vitro culture. The CD31 positive cells have invaded the dental papilla. The dental epithelium is highlighted by the white dotted line. 

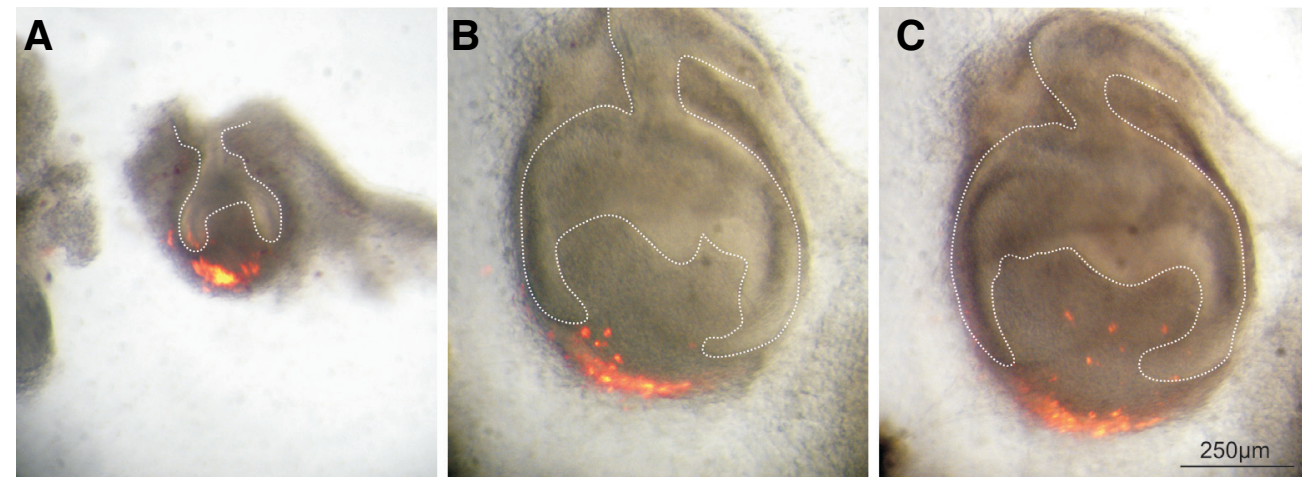

Fig. 2. Cell migration into the dental papilla. (A) E14.5 molar tooth germ. Cells at the periphery of the condensed mesenchyme labelled in red with Dil. (B) The same molar tooth germ after 3 days in vitro culture. A few Dil labelled cells have separated from the main Dil labelled region and have started to migrate towards the dental papilla. (C) The same molar tooth germ after 4 days in vitro culture. The separated Dil labelled cells have migrated further into the dental papilla. The dental epithelium is highlighted by the white dotted line. main Dil labelled area (Fig. 2B). After 4 days in culture Dil labelled cells moved further into the developing dental papilla in a dispersed manner (Fig. 2C)(migration into dental papilla observed in $\mathrm{N}=48$ cultures). This finding documents that some cells which contribute to the dental papilla at the bell stage are originally located in the periphery of the condensed dental mesenchyme at the cap stage.

\section{Mesodermal cell contribution to the developing tooth}

To analyze the origin of the Dil labelled cells migrating into the developing dental papilla in vitro we performed the same experiment as described above, using a Mesp $1 \mathrm{cre} / R 26 R$ reporter mouse. The Dil labelled cells which invaded into the dental papilla over-lapped with the X-Gal labelled mesodermally-derived cells (Fig. 3 A,B). On histological sections it is clear that the Dil labelled cells are linked to the mesodermally-derived cells, with the Dil label located along the blue labelled tracts of the mesodermallyderived tissue (Fig. 3 C,D).

To trace the mesodermal contribution to the tooth germ in vivo we looked at histological sections of the Mesp1cre/R26R reporter mouse during various stages of tooth development. At the bud to cap transition stage there were no cells of mesodermal origin in the forming dental papilla. Mesodermally-derived cells were however located in the dental follicle (i.e. in the condensed mesenchyme adjacent to the papilla and outer dental epithelium - ODE - of the enamel organ) and in surrounding tissue (Fig. 4A). A few hours later at E15.0, a few blue cells were observed in the dental papilla as the tooth germ progressed to the late cap stage (Fig. $4 B$ ). At the early bell stage (E 16.5) mesodermally-derived cells were noted not only throughout the dental follicle but also in the dental papilla, reaching up to the odontoblast layer (Fig. 4C). At postnatal stage $(P) 5$ mesodermally-derived cells were found scattered throughout the dental pulp (Fig. 4D). At P18, when the first molars have started to erupt and roots are formed, the blue

Fig. 3. Migration of mesodermally-derived cells into the dental papilla. (A) E14.5 molar tooth germ of Mesp1cre/R26R embryo. Cells at the periphery of the condensed mesenchyme labelled in red with Dil. (B) The same molar tooth germ after 4 days in culture and X-Gal staining. The Dil labelled cells (in red) entered the dental papilla. The mesodermallyderived cells are stained in blue with X-Gal. (C) Histological section of the same X-Gal stained molar tooth germ. Dil in red, mesodermally-derived cells in blue. (D) Higher magnification of the same molar tooth germ showing the Dil labelled cells linked to the blue mesodermally-derived cells in the dental papilla. The dental epithelium is highlighted by the white dotted line. stained mesodermally-derived cells marked out a crisscrossing network of cells in the dental pulp, with high concentrations located at the apex of the roots (Fig. 4E). Cells of mesodermal origin therefore enter the developing dental papilla at E15.0 and then spread throughout the forming dental pulp.

\section{Endothelial cells in the developing tooth}

The pattern of the mesodermally-derived cells at E14.5 and E16.5 (see Fig. 4 A,C) closely matched that of the endothelial cells labelled with the CD31 antibody (see Fig. 1 C,D and Fig. 5 A,B). In keeping with this, the Mesp1cre/R26R reporter has been shown to label endothelial cells which migrate throughout the head during development forming the blood vessel network (Yoshida et al. 2008). To confirm that the mesodermally-derived cells moving into the dental papilla were endothelial cells, CD31 immunohistochemistry was performed on Mesp1cre/R26R stained sections. A clear co-localisation of CD31 and mesodermallyderived cells was detected in the dental pulp (Fig. 5C), document-
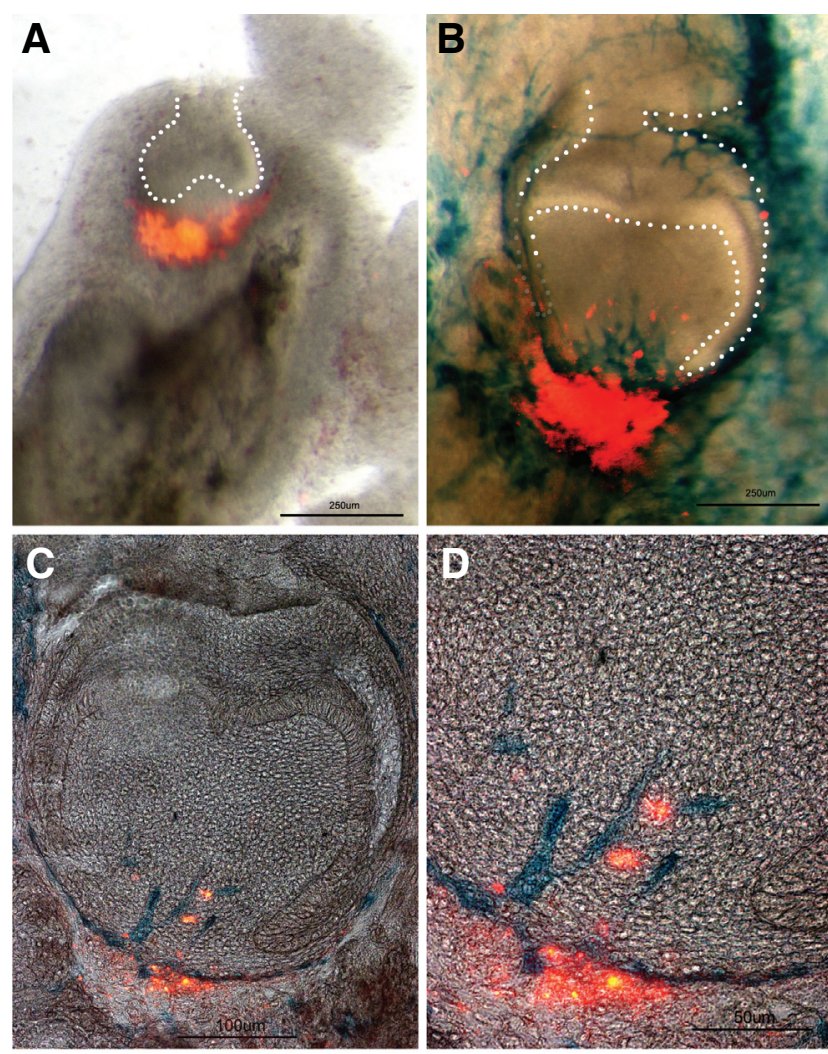

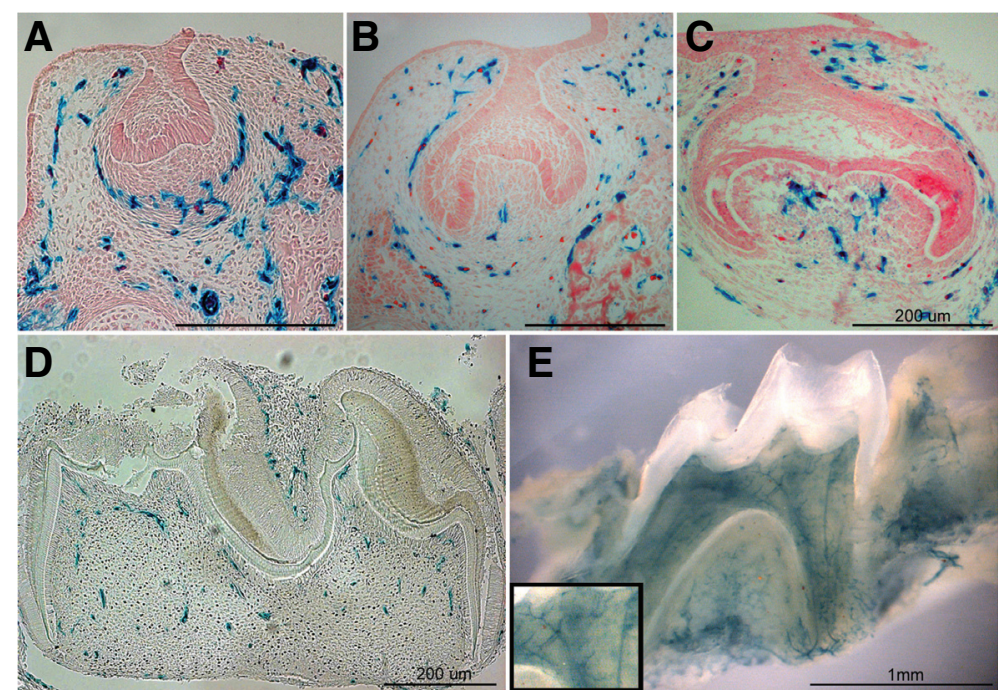

Fig. 4. Contribution of mesodermally-derived cells to molar development. The mesodermally-derived cells are stained with X-gal in blue. (A) Frontal section of molar tooth germ of E14.5 Mesp1cre/R26R embryo. There are no cells of mesodermal origin present in the dental epithelium or the adjacent condensed mesenchyme. (B) Frontal section of molar tooth germ of E15.0 Mesp1cre/R26R embryo. Single mesodermally-derived cells are found in the tooth papilla. (C) Frontal section of molar tooth germ of E16.5 Mesp1cre/R26R embryo. The mesodermally-derived cells are present in the dental papilla and the forming dental follicle. (D) Sagittal section of the first molar of Mesp1cre/R26R mouse at P5. (E) Sagittal view of the first molar of Mesp1cre/R26R mouse at P18, showing large numbers of mesodermally-derived cells in the dental pulp and at the roots with closer look at the capillary network in the frame.

ing the immigration of endothelial cells of mesodermal origin into the dental papilla.

\section{Discussion}

By culturing the Mesp1cre/R26R tooth germs in slice culture we have shown that mesodermally-derived blood vessels were able to successfully invade the dental papilla in vitro. This finding is in contrast to the lack of blood vessel invasion observed in isolated tooth germs after in vitro culture (Nait Lechguer et al. 2008). The difference between these two in vitro culture methods probably lies in the amount of tissue left surrounding the tooth germ, which is a prerequisite for the blood capillaries to invade the dental papilla. This is supported by the fact that well-formed blood vessels invaded the papilla of dissected tooth germs after subcutaneous implantation, where the implanted tooth germ is surrounded by the host connective tissue rich in blood vessels (Nait Lechguer et al. 2008). These differences also suggest that the blood vessels in the dental papilla originate by angiogenesis (generation of vessels by sprouting from pre-existing capillaries) rather than vasculogenesis (de novo formation of a vascular network from endothelial precursors) (reviewed in Byrd and Grabel 2004).

The majority of the mesodermally-derived cells appear to be CD31 positive endothelial cells which move into the tooth to provide the blood supply. Endothelial cells have been shown to be a highly invasive cell population throughout the head (Yoshida et al. 2008). During the bell stage of tooth development, the endothelial cells rapidly colonise the dental papilla reaching up to the odontoblast layer. The close relationship between the odontoblasts and peripheral capillaries of the tooth has been related to the secretory activity of the odontoblasts (Yoshida and Ohshima 1996).

At the early cap stage a network of mesodermallyderived endothelial cells sits adjacent to the dental papilla but does not enter the papilla until the late cap stage. What controls the movement of the endothelial cells into the papilla? Blood vessels growth is regulated by the Vascular Endothelial Growth Factor (VEGF) (Mustonen and Alitalo 1995). Interestingly, one of the receptors for VEGF is Neuropilin, which was first discovered as a receptor for the semaphorin family of axon guidance molecules (reviewed in Geretti et al. 2008). Semaphorin-3a is expressed in the dental mesenchyme and has been shown to have a repulsive role: by defining where axons can migrate in the tooth by inhibiting axon growth into the regions where the sema3a is expressed (Loes et al. 2001). Semaphorin members may therefore act as guidance cues for both nerves and blood vessels. Other molecular cascades involved in angiogenesis include Notch and Hedgehog signalling which can target endothelial cells directly or can stimulate blood vessel support cells to produce VEGFs. For example, addition of Sonic hedgehog promotes expression of VEGF ligands (reviewed in Byrd and Grabel 2004). In the developing tooth, low levels of VEGF have been observed in the epithelium and dental papilla at the cap stage, with levels increasing in the inner dental
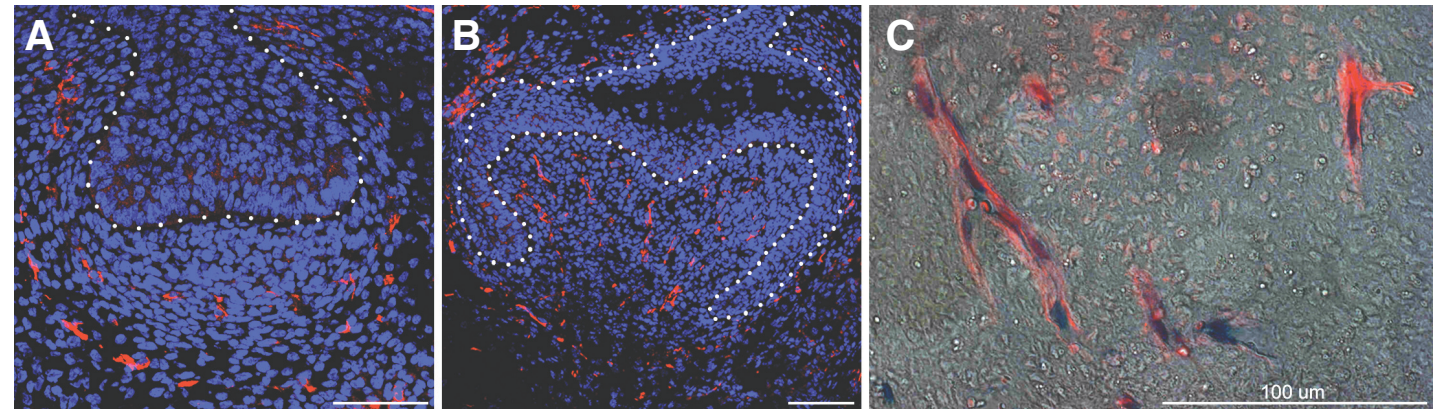

Fig. 5. Endothelial cells in the dental papilla. (A,B) Frontal section of WT embryo at (A) E14.5 (B) E16.5. CD31 positive endothelial cells are stained in red, nuclei with DAPI in blue. The CD31 pattern corresponds with the Mesp1-Cre/R26R X-gal stained molar tooth germ shown in Fig. 4 . (C) CD31 staining on Mesp 1-Cre/R26R X-gal stained sections of molar tooth germ at P5. CD31 positive endothelial cells are stained in red and are co-localized with X-gal stained blue mesodermally-derived cells. 
epithelium (IDE) at the bell stage (Aida et al. 2005). The increase in VEGF level coincides with the movement of endothelial cells into the papilla, and may play a stimulating role. The molecular mechanisms regulating blood vessels entering the dental papilla is an important question for future studies.

In conclusion, the increase of non-neural crest derived cells in the dental papilla during development is caused by the immigration of mesodermally-derived endothelial cells, which start to infiltrate the dental papilla at E15.0. No mesodermally-derived cells are present in the condensed mesenchyme before this time point. Our findings open an interesting question regarding the origin of the non-neural crest cells found at earlier stages of tooth development (Chai et al. 2000). From the Wnt1cre/R26R and Mesp1cre/R26R analysis these cells appear to be neither of neural crest nor of mesodermal origin. Thus either some other cell population contributes to the tooth mesenchyme at these early stages, or perhaps not all mesodermally or neural crest derived cells are labelled by the above-mentioned reporters.

Vascularisation of the tooth is an important process to ensure gas and metabolite exchange and therefore good vascularisation is an essential step for any attempts to bioengineer teeth (Nait Lechguer et al. 2008). Our study shows that migration of cells that will form the blood network of the tooth occurs relatively early during tooth development. Importantly blood vessel invasion can occur in vitro if the tissue surrounding the tooth germ is included in the explant. Knowledge of the timing and position of blood vessel precursors has a bearing on the health of tooth explants and the timing of implantation of bioengineered tooth germs. Our study also indicates that the Mesp1cre/R26R mice line could be an important tool in analysing the success of vascularisation in such studies.

\section{Material and Methods}

\section{CD1 mice, Mesp1cre/R26R mice}

All animals were killed using a schedule 1 method as approved by the Home Office and King's College London. The females were mated overnight and noon after the detection of the vaginal plug was considered as embryonic day (E) 0.5. For in vitro experiments and cryo-sections CD1 mice were used. The Mesp1cre heterozygous male was mated with homozygous Rosa26R female to generate the reporter line (Saga et al. 1999). Positive embryos were selected using a quick X-gal staining procedure on the embryonic bodies (20 minutes in X-Gal solution at $\left.37^{\circ} \mathrm{C}\right)$.

\section{Slice culture}

E14.5 mouse mandibles of CD1 embryos were dissected out and sliced using a Mcllwain tissue chopper (Mickle Laboratory Engineering Co., Ltd. UK) into frontal slices $250 \mu \mathrm{m}$ thick (Matalova et al. 2005; Diep et al. 2009). Slices showing a clear molar tooth cap were then selected and cultured. Slices were cultured on transparent nucleopore filters (VWR) supported on metal grids over medium. Medium consisted of DMEM F12 (Invitrogen) supplemented with 1\% penicillin/streptomycin and $1 \%$ Glutamax (Invitrogen) and 10\% fetal calf serum. Matrigel basement membrane matrix $(7 \mu \mathrm{l})$ (BD Biosciences) was added on top of the slice. Slices were cultured at $37^{\circ} \mathrm{C} / 5 \% \mathrm{CO} 2$ for $4-5$ days.

\section{Dil Labeling}

Dil is a lipophilic dye, which intercalates in the cell membrane, marking groups of cells. Dil (Molecular probes cell tracker CM-Dil, C-7000) was dissolved in $100 \% \mathrm{EtOH}$. Small amounts of Dil were injected into the slices before culture using a mouth pipette (Diep et al. 2009). The slices were then placed on filters and cultured. The position of the Dil was recorded using fluorescent Leica dissecting microscope every 24 hours.

\section{$X$-Gal staining}

Mesp1-Cre/R26R positive embryo heads were dissected to remove the lower jaws at a range of stages (E14.5, E15.0, E16.5). Excess tissue was removed prior to staining. At postnatal stages (P5 and P18) it was necessary to remove the bone and the P18 molar was cut in half to allow the X-Gal staining solution to penetrate. The tooth germs were fixed in $4 \%$ PFA for 45 minutes, washed in PBS and stained in X-Gal staining solution for 42 hours at $37^{\circ} \mathrm{C}$. The tooth germs were then post-fixed in $4 \% \mathrm{PFAO}$ / $\mathrm{N}$ and then processed through a methanol series, isopropanol and tetrahydro-naphtalene to wax. Then the tooth germs were sectioned for $10 \mu \mathrm{m}$ thickness for frontal and sagittal sections.

\section{Immuno-fluorescent staining}

For embryonic stages, the immuno-staining of CD31 antibody was performed on $10 \mu \mathrm{m}$ thick frozen sections. The heads were dissected from CD1 mouse embryos at E14.5 and E16.5 and frozen immediately in O.C.T. Tissue Tek (Sakura) diluted 1:1 with Hank's balanced solution (Sigma). Frozen sections were post-fixed in $4 \%$ PFA and processed by a Citric acid epitope retrieval method (boil in $10 \mathrm{mM}$ citric acid pH 6.5). The sections were then incubated at $4^{\circ} \mathrm{C}$ O/N with primary antibody CD31 (Rabbit polyclonal IgG to CD31, Abcam, \#Ab28364) diluted 1:150 in 1\% BSA. The secondary antibody (Alexa Fluor ${ }^{\circledR} 568$ goat anti-rabbit IgG, Invitrogen, \#A11036) was diluted 1:500 in 1\% BSA and incubated at RT for 1 hour. Nuclei were stained with Prolong ${ }^{\circledR}$ Gold anti-fade reagent with DAPI (Invitrogen).

For the postnatal stage P5, the Mesp1cre/R26R molars were embedded into wax and then sectioned for $5 \mu \mathrm{m}$ thickness. The same staining protocol as described for frozen sections was then performed.

The slices of CD1 mandibles were fixed in 4\% PFA 3hours at RT prior or after the in vitro culture, blocked in $10 \%$ goat serum in $0.1 \%$ Tween 20 (Sigma) O/N. The slices were then incubated with CD31 primary antibody (1:150 in 1\%BSA) for 6 hours, with the Alexa Fluor 568 (1:300 in 1\%BSA) secondary antibody $\mathrm{O} / \mathrm{N}$ and then stained with Hoechst (Sigma \#H6024) for 4 hours. The images were taken using Leica SP5 confocal microscope.

\section{Acknowledgements}

We thank Karen Liu and Albert Basson for the Mesp1cre and Rosa26R mice. Michaela Rothova and Renata Peterkova are funded by the Grant Agency of the Czech republic (grant CZ:GACR:GA304/07/0223) and by ÚEM AV CR - AV0Z50390512, AV0Z50390703.

Michaela Rothova performed this work during an Erasmus exchange programme with King's College London. Abigail Tucker is funded by a Royal Society international joint grant with the Czech Republic (RS 2009/ R1).

\section{References}

AIDA M, IRIÉ T, AIDA T and TACHIKAWA T (2005). Expression of protein kinases $C$ betal, betall, and VEGF during the differentiation of enamel epithelium in tooth development. J Dent Res 84(3): 234-239.

BYRD N, GRABEL L (2004). Hedgehog signaling in murine vasculogenesis and angiogenesis. Trends Cardiovasc Med 14(8): 308-313.

CHAI Y, JIANG X, ITO Y, BRINGAS P JR, HAN J, ROWITCH DH, SORIANO P, MCMAHON AP and SUCOV HM (2000). Fate of the mammalian cranial neural crest during tooth and mandibular morphogenesis. Development 127(8): 16711679.

CHO SW, HWANG HJ, KIM JY, SONG WC, SONG SJ, YAMAMOTO H and JUNG HS (2003). Lineage of non-cranial neural crest cell in the dental mesenchyme: using a lacZ reporter gene during early tooth development. J Electron Microsc 


\section{M. Rothová et al.}

(Tokyo) 52(6): 567-571.

CHO SW, LEE HA, CA J, LEE MJ, KIM JY, OHSHIMA H and JUNG HS (2007). The primary enamel knot determines the position of the first buccal cusp in developing mice molars. Differentiation 75: 441-451.

DIEP L, MATALOVA E, MITSIADIS TA and TUCKER AS (2009). Contribution of the tooth bud mesenchyme to alveolar bone. J Exp Zoolog B Mol Dev Evol312B(5): 510-517.

DIEKWISCH TGH (2002). Pathways and fate of migratory cells during late tooth organogenesis. Connect Tissue Res 43: 245-256.

GERETTI E, SHIMIZU A and KLAGSBRUN M (2008). Neuropilin structure governs VEGF and semaphorin binding and regulates angiogenesis. Angiogenesis 11: 31-39.

LOES S, KETTUNEN P, KVINNSLAND IH, TANIGUCHI M, FUJISAWA $\mathrm{H}$ and LUUKKO K (2001). Expression of class 3 semaphorins and neuropilin receptors in the developing mouse tooth. Mech Dev 101: 191-194.

MATALOVA E, ANTONARAKIS GS, SHARPE PT and TUCKER AS (2005). Cell lineage of primary and secondary enamel knots. Dev Dynamics 233: 754-759.

MCBRATNEY-OWEN B, ISEKI S, BAMFORTH SD, OLSEN BR and MORRIS-KAY GM (2008). Development and tissue origins of the mammalian cranial base. Dev Biol 322: 121-132.
MOHAMED SS, ATKINSON ME (1983). A histological study of the innervation of developing mouse teeth. $J$ Anat 136: 735-749.

MUSTONEN T, ALITALO K (1995). Endothelial receptor tyrosine kinases involved in angiogenesis. J Cell Biol 129: 895-898.

NAIT LECHGUER A, KUCLER-BOPP S, HU B, HAIKEL Y and LESOT H (2008). Vascularization of engineered teeth. $J$ Dent Res 87(12): 1138-1143.

NEWMAN PJ, BERNDT MC, GORSKI J, WHITE GC $2^{\text {ND }}$, LYMAN S, PADDOCK C and MULLER WA (1990). PECAM-1 (CD31) cloning and relation to adhesion molecules of the immunoglobin gene superfamily. Science 247(4947): 1219-1222.

SAGA Y, HATA N, KOBAYASHI S, MAGNUSON T, SELDIN MF and TAKETO MM (1996). MesP1: a novel basic helix-loop-helix protein expressed in the nascent mesodermal cells during mouse gastrulation. Development 122: 2769-2778.

SAGA Y, MIYAGAWA-TOMITA S, TAKAGI A, KITAJIMA S, MIYAZAKI J and INOUE T (1999). Mesp1 is expressed in the heart precursor cells and required for the formation of a single heart tube. Development 126: 3437-3447.

YOSHIDA S, OHSHIMA H (1996). Distribution and organization of peripheral capillaries in dental pulp and their relationship to odontoblasts. Anat Rec 245: 313-326.

YOSHIDA T, VIVATBUTSIRI P, MORRIS-KAY G, SAGA Y and ISEKI S (2008). Cell lineage in mammalian craniofacial mesenchyme. Mech Dev 125: 797-808. 


\section{Further Related Reading, published previously in the Int. J. Dev. Biol.}

See our recent Special Issue Placenta edited by Joan S. Hunt and Kent L. Thornburg at: http://www.ijdb.ehu.es/web/contents.php?vol=54\&issue=2-3

Coexpression of Notch3 and Rgs5 in the pericyte-vascular smooth muscle cell axis in response to pulp injury Henrik Lovschall, Thimios A. Mitsiadis, Knud Poulsen, Kristina H. Jensen and Annette L. Kjeldsen Int. J. Dev. Biol. (2007) 51: 715-721

Formation of a successional dental lamina in the zebrafish (Danio rerio): support for a local control of replacement tooth initiation Ann Huysseune

Int. J. Dev. Biol. (2006) 50: 637-643

BMP signalling in craniofacial development Xuguang Nie, keijo Luukko and Paivi Kettunen Int. J. Dev. Biol. (2006) 50: 511-521

Molar tooth development in caspase-3 deficient mice Eva Matalova, Paul T. Sharpe, Saquib A. Lakhani, Kevin A. Roth, Richard A. Flavell, Jana Setkova, Ivan Misek and Abigail S. Tucker Int. J. Dev. Biol. (2006) 50: 491-497

Detection of differentially expressed genes in the early developmental stage of the mouse mandible H Yamaza, K Matsuo, T Kiyoshima, N Shigemura, I Kobayashi, H Wada, A Akamime and H Sakai Int. J. Dev. Biol. (2001) 45: 675-680

A mouse mandibular culture model permits the study of neural crest cell migration and tooth development Y Chai, P Bringas, C Shuler, E Devaney, R Grosschedl and H C Slavkin Int. J. Dev. Biol. (1998) 42: 87-94

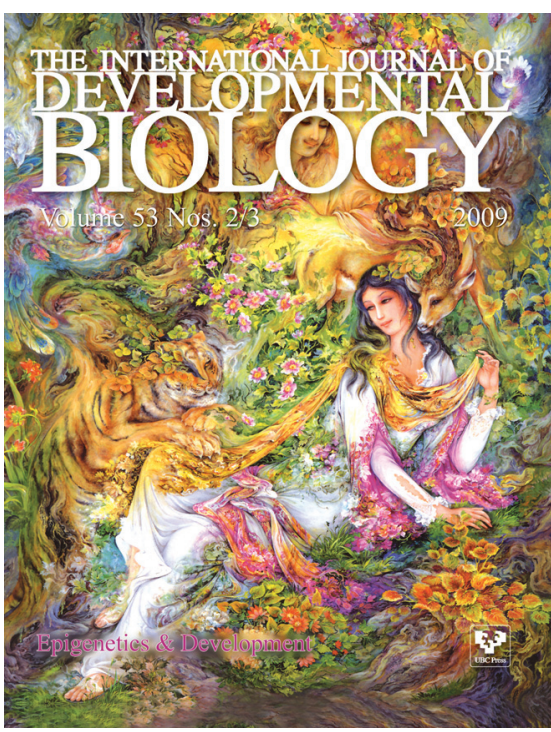

5 yr ISI Impact Factor $(2008)=3.271$

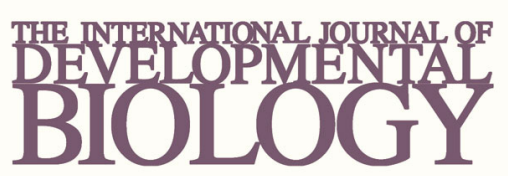

Volume 54 Nos. $6 / 7$
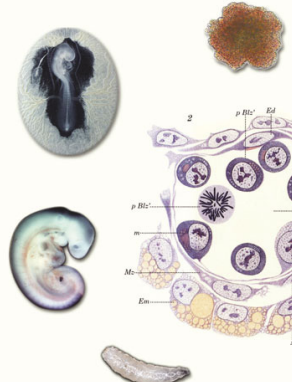

$$
\text { Special Issue }
$$

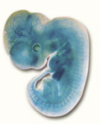

Developmental Hematopoiesis

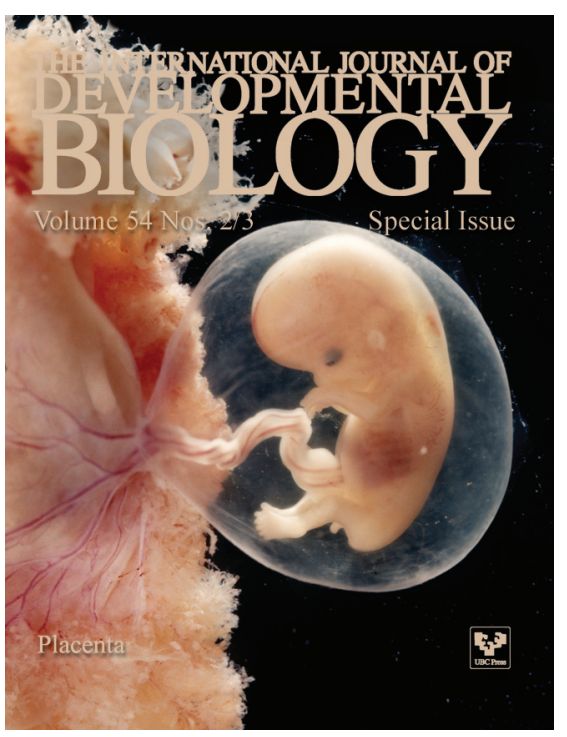

